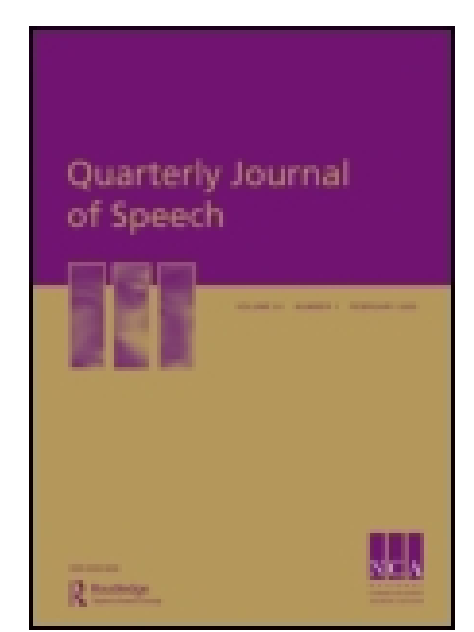

Quarterly J ournal of Speech

Publication details, including instructions for authors and subscription information:

(t).//www. tandfonline.com/loi/ rajs20

\title{
Psycho pathology of speech defects
}

Hannah Moore Creasy

a Columbia University

Published online: 05 J un 2009

To cite this article: Hannah Moore Creasy (1919) Psycho pathology of speech defects, Quarterly J ournal of Speech, 5:3, 266-278, DOI: 10. 1080/ 00335631909360747

To link to this article: http:// dx. doi.org/ 10.1080/00335631909360747

PLEASE SCROLL DOWN FOR ARTICLE

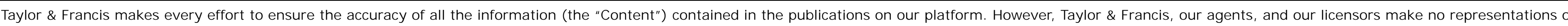

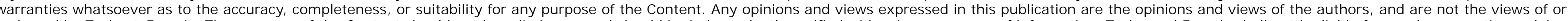

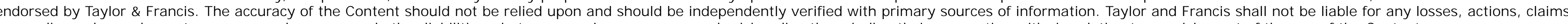
proceedings, demands, costs, expenses, damages, and other liabilities whatsoever or howsoever caused arising directly or indirectly in connection with, in relation to or arising out of the use of the Content.

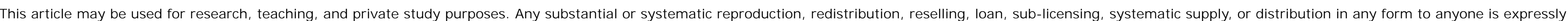
forbidden. Terms \& Conditions of access and use can be found at http://www.tandfonline.com/page/terms-and-conditions 
PSYCHO PATHOLOGY OF SPEECH DEFECTS

HANNAH MOORE CREASY

Columbia University

DATHOLOGICAL psychology, that is, abnormai psychology 1 -shows the relation between mind and body. Alexander Bain says- "It is universal testimony that our feelings or emotions have no independent spiritual substance-but are in every case embodied in our fleshly form." The mind is destined to be a double study. The mental philosopher and the physical philosopher must join hands and acknowledge that we cannot dissociate mind from body. The early fathers of the church recognized this philosophy when they taught that the soul cannot sin without the body. The medical man must not conclude that man is made of flesh and blood alone, to the exclusion, too of ten, of investigating the controlling force of life-the psyche-the soul. In the psychic, as in the physical, every effect has its cause. Nothing is chancenothing is arbitrary. Whatever is, can be traced to its cause - must have a reason.

The study of pathological psychology is leading us to see that man cannot only be studied by the microscope or felt with his hands. We realize the power of mind over body, and recognize the fact that ideas can induce both healthy and morbid changes in the system.

By thinking strongly of the stomach we can affect the local circulation of the blood-and by persistent attention-we might bring about a diseased action of that part. This philosophy is pertinent in reference to epidemics. During the epidemic of influenza the physicians and press warned us not to worry about catching the influenza, but to think of something else. Keep the system in good condition and avoid fear and the chances are you will win out. The Boston Globe and other journals pointed out that"fear is our worst enemy." In the article "How to Escape the Influenza" issued by the National Conference of Army-Navy and Civilian-Doctors-the tenth paragraph states-"Do not worry!" Remember - "The man who fights a German or a germ-he who worries is already half beaten."

The power of mind over matter is probably more marked in hysteria than in any other functional disturbance. Hysteria is a 
state in which ideas control the body producing morbid changes in its functions. Dr. Scripture, the well-known speech specialistclasses stuttering as a form of hysteria. It is a fear neurosis.

It is my endeavor in this paper to uphold the thesis that in stuttering the speech mechanism is not at fault; the trouble is in the mind. It is the mind that is tied and not the tongue. The cure therefore must be worked out in the psychic realm and not in the physical.

Someone has said- "He who knows one subject well-knows all things. Life is so correlated-so interwoven." This seems very true. Agassiz, the great naturalist, when he was dying saidthat he wished that he had spent all his life studying one insect. That would have been a sufficient life work. The human being is too complex for any one to thoroughly grasp. Man's attempts at the best must be limited. Our subject is the human being. We cannot intelligently hope to help any one of a highly strung mental mechanism-if we do not, at least, know a little of his psychology. I say this as an explanation, rather than as an apology, for the varied subjects we hope to discuss under the subject of speech defects.

Most stutterers can trace the beginning of their stuttering to a nervous shock or fright: terrifying experiences, practical jokes, falls, accidents, surgical operations, ghost stories, early illness, malnutrition, etc. When you question the parents to get the history of the case, you are often interrupted by the mother saying:- "He wasn't always like this. He never talked like this until he got that shock," and a history of the shock follows.

Some parents have a very narrow interpretation of the word "shock." I had a case at the City Hospital of a boy who had pronounced symptoms of a fear neurosis. I asked the mother if her son had ever had a shock. She insisted that he had not. I told her to think it over and we would discuss it the next time she came. The next meeting she was just as positive-declaring her boy had never had a shock of any kind. I said - "I am sorry to disagree-but I know that he has had a shock. Let us go over his life history and see what we can find." This revealed the following. At the age of nine-while serving as altar boy in the church-the lace on his robe caught fire from one of the candles. $\mathrm{He}$ was severely burned. I asked the mother if she considered 
that a shock. She said "No-that was a burn." The story also revealed that he began to stutter after the incident.

Stuttering may develop at any time of life-but it is more common among children. A child is not born with speech-it is acquired by trial and error. First come the inarticulate babblings of the infant. Gradually pathways are established between the ingoing tracts and the sensory areas of the brain, the motor areas, and the outgoing tracts, and appropriate movements in the speech mechanism. All this requires a perfectly working mechanism of the reflex arc and perfect co-ordination. This perfect co-ordination is only attained by constant practice. It is therefore readily seen why the speech mechanism of a child can be more easily affected than that of the adult, that is, a minor shock may do the damage to a child. Severe shocks such as are sustained in battle, panics, and accidents are deeply impressed - and consequent motor disabilities readily accounted for, including stuttering.

The first symptoms of stuttering that resulted from shock might have been easily corrected by an intelligent parent, but it is more often made worse by punishment and threats. The child soon finds the more effort he makes to speak correctly-the worse it becomes. These past experiences make him see nothing but trouble ahead when he tries to speak-and a compulsion-a subconscious fear attacks him every time he makes the effort.

During a shock or fright, the brain functioning may become momentarily paralyzed-so that all that apparently remains active is the emotion of fear and the complex (the thoughts, ideas, and pictures bound up with the emotion). We speak of being speechless-white as death-cold as ice-fixed stare-rigid with fright-dread - terror-all manifestations of the fear instinct.

I spoke of the emotion, the fear, momentarily remaining supreme. After the fright subsides and one is brought to himselfdamage is sometimes done. The emotion bound in its complex sinks beneath the threshold of consciousness-but it is none the less powerful and determined to be a ruling factor in the emotional life. Every time the emotional nature is aroused, this complex, this whispering voice from the secret chamber-(subconscious), may act as a disturbing agent - begging its way-as it were-for recognition-by confusing the thoughts-as though in disguise, causing a recapitulation of the original complex-e.g. Inhibitionstaring eyes-coldness, etc. This inner voice, inhibiting the will 
in some cases-attaches itself to the speech organs-resulting in a faltering, inhibited, or inco-ordinated speech known as stuttering. The question arises why do not people under equal emotional strain - e.g. fright - etc., succumb to a fear neurosis? The answer is that those who do have a fertile neurotic soil on which the neurosis develops.

Heredity plays a big part in the nervous system. Stability of nerves on one hand, or inherent weakness and exhaustion on the other, largely predestines the nervous health of the child. It is in the psychic world just as it is in the physical. Of two people exposed to tubercular or other germs why may one take the disease and the other not? The answer is the same. The victim of the germ is the one who had the non-resistance to that germthe fertile soil for its development. This sends us further back in our investigation than to the exposure and a development of a disease, and in the psychic, the fright or fixation of a neurosis. In the question of bacilli or germ infection there may be a taint of tubercular family history - or of alcohol or syphilis, that weakened the resistance; or any other factor that is apt to produce a weak or unhealthy offspring. The infection may be acquired, as in diseased tonsils-toxemia, or run down constitution. This, as I said, means a weak resistance. In the psychic it again may be due to hereditary taint:-tuberculosis-alcohol-syphilis-epilepsyhysteria, or any of the functional nervous disturbances that bestow a legacy - a poor start to the offspring.

I do not mean the child inherits any specific nervous disease, any more than it inherits the germs of tuberculosis-but it inherits the low nerve stamina-a line of weak resistance. This brings us to an important point. We speak of all stutterers being neuroticsthey are therefore not neurotic because they stutter-but stutter because they are neurotic.

It is evident then that we must trace stuttering further back than the fright stage. We must, in seeking the cause of a disease, be willing to probe deeper than the physical manifestations-the effect-and search for the cause in the psyche-the mind.

Now we arrive at another factor. It is not always hereditary taint. Frequently it is due to defective training, almost from birth, in the dominant factor of life-the emotional nature. Although the emotions, the feelings, are bound up in the intellect, the emotions have a wider and more forcible impetus. Either the 
will must govern the emotions, or the emotions will govern you. This is often done with damaging results. We must understand the emotions, the feelings, in order to control them-not to cripple them.

Because we fail to understand the emotions-fail to harness them and use them for our best development, we have a large percentage of neurotic people today. We all know-owing to the strenuous, difficult life we are leading-that mankind is becoming more and more neurotic. We are becoming too civilized without an appropriate, intelligent understanding of the emotions.

In a valuable book called "The Neighbor" written by the late Prof. W. Shaler of Harvard University, you will find this very pertinent statement. "It is hardly too much to say that all the important errors of conduct, all the burdens of men or of societies, are caused by the inadequacies in the associations of the primal animal emotions with those mental powers which have been so rapidly developed in mankind."

"Civilization is harnessing the emotions, giving up our pleasures, renunciation." Development depends upon our willingness to renounce, to fight.

Adjusting one's self to his environment means expressing the emotional nature in a healthful, active way, from childhood to death. This is difficult, for we know that in adaptation to that society, many things happen. "We are all primitive: high class animals that have been raised to high human beings." In dealing with children we must remember that it is not easy for a child to be torn from his early instincts-for fear, love, anger, cruelty, etc., are biological. These emotions are as old as the race. Fear is one of the most primitive instincts. Primitive man had to forage for food. He met wild animals and obstacles to destroy him. He learned to fear, and in his defensive, aggressiveness was begotten. If it were not for fear, he would have been killed-if it were not for fear we would be killed.

Children have a great fund of inherited fears, and some fears are acquired. Many of our gestures are survivals of ancient and forgotten fears such as warding off, avoiding, etc. Bashfulness is an interesting manifestation of fear. All emotions go in pairs, in contrast. Bravery is intermingled with some cowardice. The bravest "going over the top" felt a sense of fear. Hector ran like fury-but we surely would not call him a coward. Fears, there- 
fore, are normal and justifiable, but morbid fears are cause for alarm.

Child life is a life of resistance. The child hears continually "No," the adult ruling, "Thou shalt not." He learns to say "No" long before he says "Yes." Such frequent inhibitions stunt his powers of observation and judgment and make him hypocritical. Civilization demands hypocrisy. It is true that his emotions must be suppressed, but it must be done patiently, gradually, intelligently, if we desire an adequate expression of instinct. Not suppression, but utilizing instinct, spells progress.

Any undue emotional reaction too suddenly curbed may become introverted, forced back into the subconscious, where the dammed-up emotion, the repression, may be left to work according to rules of its own, thus causing a conflict. A conflict arises when one cannot accomplish what one will because of this inner repressed something - which holds one back. It is the skeleton in the closet-the thing he is trying to conceal. If he can find something which releases this repression, sublimate-it is well; if not, a failure to sublimate usually results in a neurosis. Too much coddling works harm to a child's emotional development. A child whose aches and pains are kissed away becomes neurotic, and later longs for sympathy. It is better for him to suffer than to be fussed over. This does not mean that a child should not receive a certain amount of affection, but it should be limited.

The only child is often diseased-because he becomes selfishintroverted-an egotist. He rarely escapes a neurosis. He is a poor competitor, not having learned it at play. This becomes a great draw-back in his business and social relations. It is equally true, however, that if carefully brought up, he may become a great leader. Self denial, self restraint, regard for the rights of others, sacrifice, service, kindness, control of the emotions, are all factors deciding the weal or woe of the character of the individual. Roosevelt's success-his eminently aggressive nature-was the result of a proper development. His emotional nature was sublimated into big things, not curbed. Aggressiveness can be expended into proper games and sports. The morale of a college depends upon the nature of its games and sports, permitting the young men to get rid of their emotional nature in a healthful, joyous way. There is a deeper psychological purpose in encouraging such games than simply giving the young men a good time. 
Incidentally, the Boy Scout movement gives a boy the opportunity to sublimate his aggressive nature.

It is selfishness in a mother that keeps the child tied to her apron strings. His love life that had its first attachment to parents should be partially withdrawn in due season-part going out to his playmates, while at puberty it is natural and right to become interested in the other sex. Schiller said "On these two pillars life rests-Love and Hunger"; Philosophy says that fundamentally life resolves itself into two things: Self preservation and Self propagation. Since the dynamic force of life (sex) is one half of our being - can we afford to ignore it? To do so would be degrading and abnormal. Sex is biological, and a natural phenomenon. Be honest with a child in regard to sex. Answer his questions truthfully. The danger lies in adding unsolicited information. Avoid it. You do not attempt to tell him all you know on other subjects: why on sex? If he asked you a question on physiology you would not attempt to give him the whole book for the first answer. He will ask you only the questions along his childhood experience. As he grows in years, he will have gathered his knowledge piecemeal, fragmentary-thus preventing a morbid curiosity and a premature development of sex. Tell him what he wants to know, but train him to control - to harness his desires. Thus will he be better fitted to live in a society which demands his control of sex. This early training must be given by mothers: but at the age of eight or nine it should be given by proper, sympathetic, and understanding teachers-not by any teacher.

Repression in childhood and in adults can be carried to excess, causing a neurosis. A neurosis may be defined as an outward visible sign of an inward conflict going on in the subconscious. Psychologists claim that all psychic neuroses are caused, primarily, by repression:-that is-the emotions did not get an adequate and natural outlet. War officials, recognizing the danger of repressed emotions incident to military discipline, condoned profanity, not to lower the morale, but in recognition of the necessity of venting the emotions. Ills come from turning our energy inward instead of outward-making it creative. Turn your emotional reactions without. Put every atom of energy at interest. Get power-creative, not thinking. To get the maximum of happiness, you must get the maximum of efficiency. Put 
your libido in your work. Get emotional outlet in your work. Sublimate!

All dreams that travel away from reality are bad influence. Train a child from the beginning to adapt himself to reality. Everything must be gotten by hard work. The "Magic Cap" can't help you to your goal. "Do noble deeds-not dream them all day long." The measure of one's selfishness is-what does it lead to?-what does it do? Is a life more selfish than social?

If the results are good you may feel assured your motives are altruistic-if the results are bad-it is egoism-self love. That is-a well organized life is altruistic and conversely-egoism leads to a poorly organized life. The latter is an introversion of the emotional outlet. The personal affairs are put ahead of the good of the whole. This is contrary to nature and begets ills. The soldier in the trench who was thinking more of self than of his responsibility to his country is an example of this.

There is always a history of emotional disturbance-of things troubling him-when he breaks down as a victim of shock neurosis. The shock or overwork that apparently caused it-is the last straw. You recall the early history of trench life and how many of the soldiers were buried in the mud due to lack of ability at that time to build trenches free from mud danger. Some Canadian soldiers were stationed to hold part of a trench of this kind and were buried in the mud for about a week. When released, the effect in each man varied: inflammatory rheumatism, pneumonia, tuberculosis, shell-shock. The circumstance suffered was common to all-yet the consequent illness differed in each case. The soldier suffering from shell-shock must have been predispositioned to a neurosis.

At the time of the Black Tom and Perth Amboy disasters, several people were taken to the hospital suffering from shock (the press termed it shell-shock), but it was really traumatic hysteria. They were neither cut nor bruised, but wrecks from shock. Had this fright been sustained in the trenches it would have been termed shell-shock. The clinical pictures do not differand the geography does not alter the case. Railroad accidents tell of a history of shocks and law suits following for damages-by people who did not get as much as a scratch. It is a matter of fine legal and medical argument to decide how much the railroad is really to blame. We may reason both ways. If the train had 
behaved well - the victim would not have received the shock-but it is equally true-if the psychic make up (the emotional state) of the individual behaved well-he would not have been affected.

There is no distinction between nervousness in soldiers and in civilians-although current literature is inclined to give the impression that "shell-shock" is a new disease. As I said before, there is nothing new in shell-shock. There is an analogy in a fear neurosis and a war neurosis. In both a neuropathic constitution found a fertile soil for a neurotic and psychic disturbance. War neurosis is a state in which ideas and wishes control the body and produce morbid changes in its functions. Statistics tell us that a large proportion of men have been disabled by shock (war neurosis), temperamentally unfit to stand the strain of the great shock incident to trench life. We know that thousands have returned to us suffering from shell-shock (hysteria) among them a large percentage of stutterers. It is interesting to note, that without exception there has never been a case of shell-shock while the men were actually fighting and in the thick of battle. It is while they are waiting and brooding, and a shell suddenly bursts-or in many cases-no real shock. Neurosis is brought on purely by mental conflict. Neurologists agreeing that there is a history of neurotic constitution in every case of shell-shock, even though it may not be obvious to the lay mind-recommended to the Government not to send any man to the front who had been known to have a neurosis. It is a risk. Neurologists knew that such a man would probably break again and become a care. A man who was afraid to go, potentially, was unfit to go. He has not enough aggressiveness to fight and was too self centered. Such men became sick. They had a neurosis-shell-shock. Their sickness was merely their subconscious way of expressing a resistance. Probably they have reacted like this in a minor degree to former problems in life. Even in childhood they probably learned that they could gain their point by getting sick. This infantile reaction continues through life, but it is subconscious. They do not know it - and they are not cowards in our sense of the word. War simply brought to the surface what was latent. If we could analyze each case we would probably find strata of determent that caused this final break in the trench. Something went wrong in infancysomething in childhood a little later, and a little later a shock brought the whole conflict to the surface. The strata may be 
likened to the weak threads in the cord-not visible-but a strong pull reveals the weakness in the cord all along the line. The clinical picture of hysteria is varied beyond description. From a slight case-perhaps merely depression -it may run the whole gamut of diseases-to the tragic consequence we are now witnessing in shell-shock. The neurologists have discovered that in every case of hysteria there is an underlying wish. That is-the patient has some difficulty that seems too hard for his management, and he is anxious to rid himself of it. His sickness, the physiological symptoms, act as an avenue of escape.

A person usually fashions his life to make things come out as he wishes them to be. If he be progressive he brings out this adjustment by intellectual processes and high ideals - sublimation. If he be not progressive and finds that his problems are too difficult for his solution, he seeks an avenue of escape by retrogressive methods: perchance an illness. Watching his symptoms, his distress may make you doubt this - but if you can gain his confidence sufficiently you will find the truth: somewhere, somehow, he is being satisfied-a wish is being fulfilled, and he gains some happiness. The patient realizes perfectly well his trials, and hopes for delivery from them-but his method of employment of escape (illness) is unconscious to him. He does not realize that his wishes can and $d o$ create a neurosis. Not consciously bringing on his illness-it is real to him. He, therefore, is not a wilful deceiverhe is not a fakir. His wishes, his urge, his inner conflict simply become too strong for him to longer keep under cover-and it found an outlet, it got its expression in symptoms and illness.

It is simply his failure in his effort of adjustment. His impulses remain infantile. He is usually of a high moral typeover honest-conscientious, but his impulses and problems of life are too difficult. He is not capable of adjusting them. A conflict arises. If he were progressive he could adjust himself to his environment. He could find means and ways of overcoming his difficulties and lead to the happiness he is seeking by intelligent and progressive methods. When he has become introvertedspending time in dreaming and self pity-his illness gives him the means of escape-and though morbid-a certain amount of happiness to him. The neurosis is a morbid gain. The disease is not commensurate with the effect. Some, therefore, gain their happiness by progressive methods (sublimation), others gain happi- 
ness by retrogressive methods (illness). They both lead to the same thing-but one is normal, the other pathological.

Very recently $\mathbb{I}$ heard of a case of a young man who had been cured of stuttering-had not stuttered for years. He began to stutter when he heard he was going to be drafted. He was made to realize that he had to "face the music" and discontinued it.

Hysteria may attack any motor activity of the body, or it may assimilate any or all diseases. In some cases it attaches itself to speech, causing stuttering. You may be aware that the government had a hospital at Cape May for the correction of this defect among its soldiers.

The convulsive twitching-over innervation of legs-armshead and facial muscles - the lack of co-ordinating ability in legs and hands, all favor the argument that there is an analogy between the war neuroses and stuttering, and differ probably only in degree and tenseness of exciting causes. In fact-I have had severe cases of stuttering when the convulsive movements were most marked-the tongue and eyes rolling back-the facial muscles working and an appearance of a convulsion. This happened every time the patient tried to speak. The war neurosis and speech defect have the same neurotic background-though differing in manifestation. War is like an $\mathrm{X}$ ray. It brings everything to the surface. It does not cause shell shock or insanity-but it brings it to the surface. Shell-shock exposed it.

This war neurosis-disabling thousands of the soldiers, should make us pause and think of the necessity of more intelligence in bringing up children in respect to their emotional nature. Bring them up emotionally healthy, in order that we may not have so many of the hysterical type. Let us be more truthful - more honest with them and have less shams. Let him unfold as a bud or flower-not tearing him apart-not crushing him by inhibitions and shams. Man is the product of his environment. His character is nothing but the sum total of his experiences. He is what he is because some one has erred somewhere in directing his unfolding. It was too late in warfare to hope that military discipline could change a molly coddle. War found that it more of ten breaks him. These afflicted men are in no way to blame. They must be treated kindly. They want sympathy - give it to thembut with the sympathy give them insight - that is, show them that they gain nothing by running away from reality. They must 
learn to take their place in the world-and fight their difficultiesnot let their difficulties overcome them.

We, who as teachers, are interested in the correction of speech defects-have a responsibility beyond the mere pedagogical methods used in the cure. We must have a knowledge of this emotional nature-in order to help parents and educators to more intelligently train the child. We must save him from the underlying causes that lead to pathological conditions of speechor any of the manifold types of nervous disorders-that have their origin in the same soil.

You have read of the splendid and wonderful things our Government is doing for our soldiers in respect to every department of work - and not the least is the Reconstruction Department. Expert Neurologists worked zealously to correct the traumatic convulsions and other physiological and psychological symptoms caused by the war neurosis. This was done immediately upon the admittance of the patient to the Base Hospital. These noted physicians knew the danger of allowing the disturbance to become a habit or the mental conflict to become fixed. The stutterers were sent, too, for immediate help. In fact, most cases of shell-shock were accompanied by speech defect-stuttering-hysterical aphonia, etc. Uncle Sam knows the danger of delay, and in so far as medical science can achieve it, the Government proposes to restore every injured man to his normal state, making him capable of again taking his place in the social and economic world.

Can we afford to neglect our responsibility in the schools until the child grows to manhood or womanhood-the habit of stuttering firmly fixed and the person arrived at what is termed the "Age of Indifference?" They have then ceased to recognize or care that they stutter. Stuttering in childhood is easily cured. The mother should correct the defect before the child goes to school. This we cannot directly manage-but we can-indirectly. We must begin in the schools-especially in the lower grades. We cannot over emphasize our responsibility in this matter. Ask mothers to visit you and watch the progress-not only to co-operate with the teacher but to bridge the home and school life-and the parents to become acquainted with your methods.

There will never be a time when our work will be more neededand never a time when intelligent handling will be more essen- 
tial-and by this I mean - the need of a broad knowledge of our work-including a knowledge of the nervous system and the emotional nature of man. Stuttering is an effect-and no one can cure an effect until he understands the cause. The success of our work depends upon skillful diagnosing. Each patient becomes a personal equation. The treatment is done by pedagogical methods to a large extent, but a study of neurology and psychopathology are essential to the work, not that we may become neurologists or psychologists-but in order to intelligently understand each case. Our ideals must be high and altruistic, not circumscribing our work by our methods and limitations - but recognizing the great complexity of the human being-co-operating with the physicians and constantly searching for the truth. 